\title{
DESEMPENHO E ATIVIDADE DE LIPASE EM TILÁPIAS DO NILO
}

\author{
PERFORMANCE AND LIPASE ACTIVITY IN NILE TILAPIA
}

\author{
Moura, G.S. ${ }^{1 A *}$, Oliveira, M.G.A. ${ }^{2}$ e Lanna, E.A.T. ${ }^{1 B}$ \\ ${ }^{1}$ Departamento de Zootecnia. Universidade Federal de Viçosa (UFV). Viçosa, MG. Brasil. \\ A*mouraguilherme@yahoo.com.br; ${ }^{B}$ elanna@ufv.br \\ ${ }^{2}$ Instituto de Biotecnologia Aplicada para a Agropecuária. Universidade Federal de Viçosa (UFV). Viçosa, \\ MG. Brasil.malmeida@ufv.br
}

\section{PaLAVRAS CHAVE ADICIONAIS}

Enzimas. Fisiologia de peixes. Nutrição de peixes. Oreochromis niloticus.

\section{RESUMO}

Objetivou-se avaliar os efeitos da temperatura no desempenho e na atividade de lipase de tilápias do Nilo, linhagem Tailandesa. Odelineamento experimental foi inteiramente casualizado, com quatro tratamentos $\left(20,24,28\right.$ e $\left.32^{\circ} \mathrm{C}\right)$, seis repetições e 10 peixes por unidade experimental (aquário). Utilizou-se a mesma dieta para todos os tratamentos. Aos 55 dias do experimento foi avaliado o consumo de ração aparente, o ganho de peso, a conversão alimentar aparente, a atividade de lipase e a atividade específica de lipase. O consumo de ração aparente e o ganho de peso aumentaram linearmente $(p<0,01)$ com o incremento da temperatura. Para a conversão alimentar aparente foi observado efeito quadrático em função da temperatura com melhora na conversão de 1,79 a 1 com o aumento da temperatura até $29,15^{\circ} \mathrm{C}$. Efeito linear crescente $(p<0,01)$ também foi observado para atividade de lipase e atividade específica de lipase em função da temperatura, com maior atividade a $32^{\circ} \mathrm{C}$. Conclui-se que a temperatura da água influencia o desempenho e a atividade de lipase de tilápias do Nilo.

\section{SUMMARY}

The objective was to evaluate the effects of temperature on performance and activity of lipase in the Nile tilapia, Thai lineage. The experimental design was completely randomized with four treatments $\left(20,24,28\right.$ and $\left.32^{\circ} \mathrm{C}\right)$, six replicates and ten fishes per experimental unit. The diet was

Recibido: 27-2-09. Aceptado: 23-2-12.

\section{AdDitional KEYWORDS}

Enzymes. Fish physiology. Fish nutrition. Oreochromis niloticus.

the same for all treatments. At 55 days of experiment were evaluated apparent feed intake, weight gain, apparent feed conversion, lipase activity and specific lipase activity. The apparent feed intake and weight gain increased linearly with temperature increase. For apparent feed conversion, quadratic effect was observed as a function of temperature, showing a conversion improvement of 1.79 to 1.00 with the increase of the temperature until $29,15^{\circ} \mathrm{C}$. Linear effect in lipase and specific lipase activities was observed too as a result of temperature, comprising high lipase activity at $32^{\circ} \mathrm{C}$. Water temperature influences the performance and amylase activity in Nile tilapia.

\section{INTRODUÇÃO}

A temperatura da água é um dos fatores que podem influenciar o desempenho de animais aquáticos. Os peixes, por serem animais ectotérmicos, estão sujeitos a alterações no seu metabolismo fisiológico, pois os processos de digestão são influenciados pelo meio onde vivem. Portanto, para cada espécie de peixe, existe uma faixa de temperatura em que esses expressam um maior potencial de crescimento (Piedras et $a l ., 2004)$. Isso foi confirmado em um experimento com juvenis de tainhas (Mugil brasiliensis), o qual foi observado melhora na taxa de crescimento e conversão alimen- 
tar quando estes peixes foram submetidos a $30^{\circ} \mathrm{C}$ (Okamoto et al., 2006). Também foi verificado em juvenis de largemouth bass (Micropterus salmoide) redução na eficiência alimentar e no crescimento quando estes peixes foram submetidos à temperatura de $20^{\circ} \mathrm{C}$ (Tidwel et al., 2003).

Além da temperatura, a eficiência de utilização dos alimentos pelos peixes está diretamente relacionada ao processo digestivo, no qual as enzimas são fundamentais. A lipase é uma das enzimas de origem pancreática que agem no intestino atuando nos lipídeos presentes no quimo, liberando ácidos graxos e glicerol, os quais desempenham importantes funções energéticas, estruturais e hormonais no organismo.

A atividade de lipase tem sido detectada ao longo do trato digestório de várias espécies de peixes durante as diferentes fases do ciclo de vida (Koven et al., 2003). Sklan et al. (2004) citaram que a atividade de lipase e a estrutura e a função intestinal em tilápias do Nilo (Oreochromis niloticus) são similares aos mamíferos. Avaliando os perfis enzimáticos de três espécies de peixes, Seixas et al. (2000) concluíram que os valores de atividade específica de lipase maiores para o piau-três-pintas (Leporinus friderici) em relação ao surubim (Pseudoplatystoma curuscans) e piracanjuba (Brycon orbignyanus) pode ser devido a um balanceamento energético inadequado da dieta.

O conhecimento da atividade de enzimas em diferentes temperaturas pode vir a ser uma ferramenta para auxiliar nos estudos de exigências nutricionais e nas formulações de rações para peixes. Devido aos diferentes hábitos alimentares e ambientes aquáticos, cada espécie possui particularidades fisiológicas desenvolvidas para aquela situação. Com isso, cada espécie de peixe possui o seu perfil enzimático, sendo importante o seu estudo de forma específica.

O objetivo deste trabalho foi avaliar a atividade de lipase e o desempenho de tilápias-do-Nilo (Oreo-chromis niloticus) submetidas a quatro temperaturas.

\section{MATERIAL E MÉTODOS}

O experimento foi conduzido no Laboratório de Nutrição de Peixes do Departamento de Zootecnia da Universidade Federal de Viçosa (UFV) no período de 27/07/2005 a 20/ 09/2005.

O sistema de recirculação foi formado por quatro reservatórios de polietileno, com capacidade de $500 \mathrm{~L}$ de água cada. O abastecimento de cada reservatório foi feito por gravidade, sendo o nível da água controlado individualmente. Estes reservatórios abasteceram, por bombeamento contínuo, quatro fileiras de seis aquários de $100 \mathrm{~L}$ cada, que corresponderam às unidades experimentais.

Para manter a temperatura de cada unidade experimental, o controle da vazão foi regulado com o intuito de compensar as perdas de calor do sistema. O volume de água que abastecia os aquários retornava aos reservatórios por meio de sifão articulado em cada aquário, que conduzia a água efluente para tubulações de retorno. Estas, por sua vez, devolviam a água para os reservatórios, fechando, assim, o circuito.

Foram utilizados filtros, acoplados às moto-bombas, visando evitar a recirculação de partículas em suspensão, remover a amônia residual e evitar o desgaste das unidades formadoras do sistema de recirculação.

Em cada reservatório, foi instalada uma resistência elétrica tubular blindada de $3000 \mathrm{~W}$ para o aquecimento da água. Cada resistência foi acionada por um controlador digital de temperatura (termostato), com ajuste diferencial de $-0,3^{\circ} \mathrm{C}$, programado para as respectivas temperaturas testadas.

A cada aquário, foi fornecida aeração suplementar por meio de um aerador central, evitando diferenças nos níveis de oxigênio dissolvido na água. Dessa forma, foi possível compensar as perdas de oxigênio devido à temperatura, mantendo-se os níveis próximos à saturação em todos os aquários.

Diariamente, a limpeza dos aquários e 


\section{DESEMPENHO DE TILÁPIAS DO NILO}

dos reservatórios foi feita por sifonagem do fundo, além da troca dos filtros. A temperatura da água foi aferida diariamente, às 18:00 $\mathrm{h}$, com o auxílio de termômetro digital e os níveis de oxigênio da água e o $\mathrm{pH}$ foram medidos semanalmente com o auxílio de peagâmetro e oxímetro digitais portáteis, respectivamente.

Foram utilizados 240 alevinos machos de tilápia do Nilo, da linhagem Tailandesa, com peso inicial de $0,835 \pm 0,004 \mathrm{~g}$, distribuídos em 24 aquários, com 10 indivíduos por unidade experimental. Após a distribuição, os termostatos foram ajustados para que a água, a partir de $24^{\circ} \mathrm{C}$ (temperatura de origem), atingisse as respectivas temperaturas nas quais os animais seriam mantidos, numa taxa de aumento de $1^{\circ} \mathrm{C}$ a cada seis horas. Assim, após 48 horas, todas as temperaturas-teste: $20,24,28$ e $32^{\circ} \mathrm{C}$ estavam estabilizadas. $\mathrm{O}$ início do experimento foi considerado a partir deste momento.

O delineamento experimental foi inteiramente casualizado, com quatro tratamentos (temperaturas-teste de $20,24,28$ e $32^{\circ} \mathrm{C}$ ), com seis repetições e 10 peixes por unidade experimental.

Os peixes receberam a mesma dieta à vontade (tabela I), fornecida quatro vezes ao dia (8:30 h, 11:30 h, 14:30 h e 17:30 h), evitando-se as sobras. Aos 55 dias de experimento, foram avaliados o consumo de ração aparente (g), o ganho de peso (g) e a conversão alimentar aparente.

O consumo de ração aparente, em cada tratamento, foi calculado através do peso inicial da dieta menos o peso da sobra dessa mesma dieta, ao final do experimento. Quanto ao ganho de peso, o seu cálculo foi obtido através da média do peso final menos a média do peso inicial dos peixes, em cada tratamento. A conversão alimentar aparente foi calculada dividindo-se o consumo de ração pelo ganho de peso das tilápias, nos respectivos tratamentos.

$\mathrm{Na}$ análise da atividade de lipase e atividade específica de lipase, as tilápias foram retiradas e, imediatamente, colocadas
Tabela I. Composição da dieta experimental. (Composition of experimental diet).

\begin{tabular}{lc}
\hline Composição & Quantidade (\%) \\
\hline Farelo de soja & 51,193 \\
Milho & 32,709 \\
Glúten 60 & 10,104 \\
Óleo de soja $^{\text {Fosfato bicálcico }}$ & 1,899 \\
Premix vitamínico $^{1}$ & 3,025 \\
Premix mineral $^{1}$ & 0,400 \\
Vitamina C $_{\text {Sal }}$ & 0,100 \\
Antioxidante (BHT) & 0,050 \\
Total & 0,500 \\
& 0,020 \\
\end{tabular}

Composição calculada²

$\begin{array}{lc}\text { Proteína bruta (\%) } & 32,00 \\ \text { Proteína digestível }(\%)^{3} & 29,09 \\ \text { Energia digestível }\left(\mathrm{kcal} \mathrm{kg}^{-1}\right)^{3} & 3000,00 \\ \text { Extrato etéreo (\%) } & 4,17 \\ \text { Ácido linoléico } & 2,14 \\ \text { Fibra bruta (\%) } & 3,44 \\ \text { Cálcio total (\%) } & 0,89 \\ \text { Fósforo disponível (\%) } & 0,60 \\ \text { Lisina total }(\%)^{5} & 1,598 \\ \text { Lisina digestível }(\%)^{5} & 1,450 \\ \text { Met. + Cist. total }(\%)^{6} & 1,016 \\ \text { Met. + Cist. digestivel }(\%)^{6} & 0,953 \\ \text { Treonina total }(\%) & 1,228 \\ \text { Treonina digestível (\%) } & 1,102 \\ \text { Triptofano total }(\%) & 0,372 \\ \text { Triptofano digestível (\%) } & 0,343\end{array}$

'Suplemento vitamínico e mineral comercial para peixes. Níveis de garantia (por $\mathrm{kg}$ do produto): Vit. A: 1200000 UI; Vit. B1: 4800 mg; Vit. B12: 4,8 mg; Vit. B2: 4800 mg; Vit. B6: 4800 mg; Vit. C: 48 g; Vit. D3: 200000 Ul; Vit. E: 1200 mg; Vit. K3: 2400 mg; Ácido fólico: $1200 \mathrm{mg}$; Biotina: $48 \mathrm{mg}$; Pantotenato de cálcio: $12000 \mathrm{mg}$; Cloreto de colina: 108 g; Niacina: 24000 mg; Selênio: 100 mg; lodo: 100 mg; Cobalto: $10 \mathrm{mg}$; Cobre: $3000 \mathrm{mg}$; Ferro: 50000 mg; Manganês: 20000 mg; Zinco: 30000 mg; Veículo Q.S.P.: $1000 \mathrm{~g}$; Antioxidante: $25 \mathrm{~g}$; ${ }^{2}$ Valores estimados com base nos coeficientes de digestibilidade dos ingredientes segundo Rostagno et al. (2005); ${ }^{3} \mathrm{NRC}$ (1993); ${ }^{4}$ Ribeiro et al. (2006); ${ }^{5,6}$ Furuya et al. (2006). 
em banho de gelo para morte e paralisação das atividades enzimáticas, totalizando seis amostras de cada tratamento. Os peixes sofreram incisão longitudinal ventral, com posterior isolamento da porção cranial do esôfago e da porção caudal do reto, por meio de ligaduras duplas, para evitar o extravasamento do quimo das regiões a serem estudadas. Após o isolamento, o intestino médio e posterior foram retirados e acondicionados em frascos de polietileno. Este material foi imediatamente congelado e armazenado em freezer a $-8^{\circ} \mathrm{C}$

As análises de atividade de lipase foram realizadas no Laboratório de Enzimologia, Bioquímica de Proteínas e Peptídeos do Instituto de Biotecnologia Aplicada à Agropecuária (Bioagro) da UFV no período de 21/9/2005 a 20/1/2006.

Para as análises, utilizou-se $0,5 \mathrm{~g}$ de cada amostra congelada e 1,5 mL de tampão (Tris$\mathrm{HCl}$ 0,1 M), para descongelamento e maceração. Em seguida, esse material foi centrifugado a $15000 \mathrm{rpm}$ por 15 minutos a $4^{\circ} \mathrm{C}$ e o sobrenadante utilizado para as determinações da atividade de amilase em duplicata.

As atividades foram determinadas por intermédio de um kit BIOCLIN, com metodologia modificada de Cherry and Crandall Jr. (1932), que consiste na verificação da atuação da lipase do quimo sobre um éster de glicerol, liberando um cromogênio, que é quantitativamente determinado em espectrofotometria óptica a 410 $\mathrm{nm}$. A intensidade de cor formada é proporcional à atividade de lipase e os valores são expressos em Unidades Internacionais (UI). Para obter a atividade específica de lipase, os valores da atividade de lipase foram divididos pela proteína total corrigida.

A concentração de proteína da amostra foi medida em espectrofotômetro óptico na absorvância de $280 \mathrm{~nm}$. A presença de resíduos de tirosina, triptofano e ácidos nucléicos causam interferências nas leituras ópticas. Este problema foi solucionado fazendo uma leitura a $260 \mathrm{~nm}$, pois os ácidos nucléicos absorvem mais fortemente a luz neste comprimento de onda. A razão destes dois valores foi determinada e usada para selecionar um fator correção. A absorvância de $280 \mathrm{~nm}$ foi multiplicada por este fator e com isso, a concentração de proteína, em mg. $\mathrm{mL}^{-1}$, foi obtida (Warburg e Christian, 1941).

Os dados foram submetidos à análise de variância e regressão linear com o auxílio do programa SAEG(UFV, 2004).

\section{RESULTADOSEDISCUSSÃO}

O sistema de recirculação foi eficiente para manter a qualidade da água em níveis aceitáveis (tabela II) de acordo com Boyd (1982), Piper et al. (1982) e Kubitza (2000).

Os parâmetros avaliados de desempenho e atividade de lipase em função da temperatura se encontram na tabela III. Com a elevação da temperatura houve aumento linear $(\mathrm{p}<0,01)$ no consumo de ração aparente pelas tilápias, mostrando que este fator pode interferir no desempenho.

Este resultado foi semelhante ao observado por Dias-Koberstein et al. (2004), que em pacus (Piaractus mesopotamicus), o consumo diário de ração também foi influenciado pela temperatura, proporcionando índices de ingestão de 2,29 e 2,97\% do peso vivo ao dia, para as temperaturas de

Tabela II. Temperatura (T), oxigênio dissolvido (OD) e pH da água durante o periodo experimental. (Temperature $(\mathrm{T})$, dissolved oxygen (OD) and $\mathrm{pH}$ of water during the experimental period).

\begin{tabular}{lcccc}
\hline $\begin{array}{l}\text { Variáveis } \\
\text { físico-químicos }\end{array}$ & $20^{\circ} \mathrm{C}$ & $24^{\circ} \mathrm{C}$ & $28^{\circ} \mathrm{C}$ & $32^{\circ} \mathrm{C}$ \\
\hline $\mathrm{T}\left({ }^{\circ} \mathrm{C}\right)$ & 20,53 & 24,04 & 27,92 & 31,76 \\
$\mathrm{CV}(\%)$ & 2,270 & 0,650 & 0,640 & 0,630 \\
$\mathrm{OD}\left(\mathrm{mg} \cdot \mathrm{L}^{-1}\right)$ & 7,20 & 6,80 & 6,60 & 6,50 \\
$\mathrm{CV}(\%)$ & 1,324 & 1,720 & 3,202 & 4,287 \\
$\mathrm{pH}$ & 6,58 & 6,18 & 6,36 & 6,29 \\
$\mathrm{CV}(\%)$ & 1,931 & 3,420 & 3,299 & 2,437 \\
\hline
\end{tabular}


Tabela III. Consumo de ração aparente (CRA), peso inicial (PI), peso final (PF), ganho de peso (GP) e conversão alimentar aparente (CAA), atividade de lipase (ATL), atividade específica de lipase (AEL) e proteína bruta presente no quimo (PBQ) de tilápia do Nilo em função da temperatura. (Apparent feed intake (CRA), initial weight (PI), final weight (PF), eight gain (GP), apparent feed conversion (CAA), lipase activity, specific lipase activity and crude protein of chime of Nile tilapia as a function of temperature).

\begin{tabular}{lcccccc}
\hline & \multicolumn{5}{c}{ Temperatura $\left({ }^{\circ} \mathrm{C}\right)$} & \multicolumn{2}{c}{ Ponto de } & CV (\%) \\
& 20 & 24 & 28 & 32 & inflexão $\left({ }^{\circ} \mathrm{C}\right)$ & \\
\hline $\mathrm{CRA}(\mathrm{g})^{1}$ & 41,3 & 150,2 & 302,6 & 424,3 & - & 22,746 \\
$\mathrm{PI} \mathrm{(g)}$ & 0,831 & 0,832 & 0,840 & 0,838 & - & - \\
$\mathrm{PF}(\mathrm{g})^{2}$ & 3,135 & 14,088 & 29,813 & 48,589 & - & 12,117 \\
$\mathrm{GP}(\mathrm{g})^{3}$ & 2,30 & 13,26 & 28,97 & 47,75 & - & 12,574 \\
$\left.\mathrm{CAA}(\mathrm{g} \mathrm{g})^{-1}\right)^{4}$ & 1,79 & 1,15 & 1,10 & 1,04 & 29,15 & 9,076 \\
$\mathrm{ATL}(\mathrm{Ul})^{5}$ & 148,36 & 229,00 & 360,93 & 406,11 & - & 2,797 \\
$\mathrm{AEL}\left(\mathrm{Ul} \cdot \mathrm{mg}^{-1}\right)^{6}$ & 918,07 & 1147,87 & 1306,30 & 1391,74 & - & 3,807 \\
$\mathrm{PBQ}\left(\mathrm{mg} \cdot \mathrm{mL}^{-1}\right)^{7}$ & 0,1616 & 0,1995 & 0,2763 & 0,2918 & - & 5,384 \\
\hline
\end{tabular}

${ }^{1}$ Efeito linear $(p<0,01): Y=-616,5210+32,5460 T ; R^{2}=0,99$.

${ }^{2}$ Efeito linear $(p<0,01): Y=-74,3504+3,77571 T ; R^{2}=0,99$.

${ }^{3}$ Efeito linear $(p<0,01): Y=-75,1652+3,77492 T ; R^{2}=0,99$.

${ }^{4}$ Efeito quadrático $(p<0,01): Y=8,99913-0,54887 T+0,009413 T^{2} ; R^{2}=0,95$.

${ }^{5}$ Efeito linear $(p<0,01): Y=22,6291+302,258 T ; R^{2}=0,97$

${ }^{6}$ Efeito linear $(p<0,01): Y=39,2173+173,223 T ; R^{2}=0,96$.

${ }^{7}$ Efeito linear $(p<0,01): Y=0,01169+0,07158 T ; R^{2}=0,95$.

23 e $27^{\circ} \mathrm{C}$, respectivamente. Além disso, os valores de tempo de trânsito gastrintestinal foram influenciados pelas temperaturas, com médias de 36 e 14 horas, para 23 e $27^{\circ} \mathrm{C}$, respectivamente, e a digestão do alimento foi mais lenta a $23^{\circ} \mathrm{C}$ do que a $27^{\circ} \mathrm{C}$, que alcançou menores índices de repleção. Estudando o desempenho de jundiás (Rhamdia quelen) em três temperaturas (20, 23 e $26^{\circ} \mathrm{C}$ ), Piedras et al. (2004) observaram que o consumo de ração foi influenciado pela temperatura da água. Porém, o maior consumo foi a $23^{\circ} \mathrm{C}$, mostrando que esta temperatura proporciona melhor conforto térmico para esta espécie.

Quanto ao ganho de peso, foi observado efeito linear $(p<0,01)$ em função da temperatura. $\mathrm{O}$ aumento do consumo de ração associado à elevação no metabolismo dos peixes ocasionados pela temperatura proporcionou um maior ganho de peso. As tilápias criadas a $32^{\circ} \mathrm{C}$ tiveram um ganho de peso médio de $45,45 \mathrm{~g}$ a mais do que as tilápias submetidas à menor temperatura. Em outro trabalho similar alevinos de tilápias submetidos às temperaturas de $23,26,29 \mathrm{e}$ $32^{\circ} \mathrm{C}$ obtiveram ganho de peso médio de 6,8 ; 11,$2 ; 14$ e 14,4 g, respectivamente (Justin et al., 2005). Avaliando o desempenho de catfish (Ictalurus punctatus), Piedras et al. (2006) observaram que os peixes criados à temperatura de $26^{\circ} \mathrm{C}$ ganharam 104 e $48 \%$ mais peso do que os peixes mantidos a $20 \mathrm{e}$ $23^{\circ} \mathrm{C}$, respectivamente. Foi observado em tiger puffer (Takifugu rubripes), que o ganho de peso somente aumentou com a elevação da temperatura de 25 para $30^{\circ} \mathrm{C}$, reduzindo após esta faixa térmica (Kikuchi et al., 2006). Em tainhas (Mugil platanus), o crescimento em peso e comprimento foi diretamente proporcional à temperatura, com um melhor resultado a $30^{\circ} \mathrm{C}$ (Okamoto et al., 2006). 
Para conversão alimentar aparente, foi observado efeito quadrático $(\mathrm{p}<0,01)$ em função dos tratamentos, com melhora de 1,79 a 1,0 com o aumento da temperatura até $29,15^{\circ} \mathrm{C}$, com tendência de piorar a partir desse valor. Baldisseroto (2002) citou que as temperaturas pelas quais são verificadas as maiores taxas de consumo de alimento, resultando em crescimento máximo, em geral, não correspondem a melhores resultados de conversão alimentar. Estas observações ficaram evidentes neste trabalho, pois o ganho de peso aumentou linearmente $(p<0,01)$ enquanto a conversão alimentar melhorou somente até $29,15^{\circ} \mathrm{C}$. Resultados semelhantes foram observados em largemouth black bass (Micropterus salmoides), onde o crescimento foi pior a $20^{\circ} \mathrm{C}$ e similar entre 26 e $32^{\circ} \mathrm{C}$, mas a conversão alimentar foi mais eficiente na temperatura intermediária (Tidwell et al., 2003).

Houve aumento linear $(p<0,01)$ da atividade de lipase com aumento da temperatura da água. A atividade de lipase foi 2,74 vezes maior na temperatura de $32^{\circ} \mathrm{C}$ quando comparada ao tratamento térmico mais baixo $\left(20^{\circ} \mathrm{C}\right)$. Este resultado corrobora com Moura et al. (2009), que observaram aumento de $36,7 \%$ na atividade de tripsina quando tilápias do Nilo foram submetidas à temperatura de $32^{\circ} \mathrm{C}$ em comparação às tilápias mantidas na temperatura de $20^{\circ} \mathrm{C}$.

O resultado deste experimento também sugere que o consumo de ração pode ter influenciado a atividade de lipase. A temperatura de $32^{\circ} \mathrm{C}$, as tilápias consumiram mais, o que levou ao intestino maiores quantidades de lipídeos. Esta maior concentração de substrato pode ter estimulado o pâncreas a produzir maiores quantidades de lipase, aumentando a eficiência de aproveitamento dos lipídeos. Com o melhor aproveitamento do lipídeo como fonte energética, a proteína foi poupada para a função estrutural, ou seja, desenvolvimento dos tecidos. Isto refletiu no desempenho das tilápias com o aumento da temperatura, o que proporcionou um maior ganho de peso e uma melhor conversão alimentar.

Em duas espécies de bagre (Clarias gariepinus e Heteropneustes fossilis), Usmani e Jafri (2002) verificaram que a digestibilidade da proteína e de outros nutrientes das rações melhorou com a elevação da temperatura de $18^{\circ} \mathrm{C}$ para $28^{\circ} \mathrm{C}$. Também foi observado por Azevedo et al. (1998) melhora na digestibilidade da dieta de truta arco-íris (Oncorhynchus mykiss) ao se elevar a temperatura, gradativamente, de $6^{\circ} \mathrm{C}$ para $15^{\circ} \mathrm{C}$. Silva e Araújo Lima (2003), concluíram que o tamanho de piranha-caju (Pygocentrus nattereri) não influenciou a digestibilidade de músculo de peixe, mas a temperatura agilizou a digestão, reduzindo o tempo de esvaziamento gástrico.

Quanto à atividade específica da lipase, também houve aumento linear $(p<0,01)$ em relação à temperatura. Ao elevar a temperatura, a atividade da lipase foi aumentando e a atividade específica também, mostrando que o pâncreas produz esta enzima de acordo com a quantidade de substrato que chega ao duodeno, conforme foi discutido acima. Porém, com a temperatura de $32^{\circ} \mathrm{C}$, houve uma maior eficiência na utilização dos nutrientes pelos peixes devido ao aumento da ação catalítica da lipase. Desta forma, o pâncreas não produziu lipase em proporções diretas ao consumo de lipídeos. Esta redução na produção da enzima é uma medida poupadora de energia e proteína, fazendo com que estes sejam utilizados para o fim que é proposto, ou seja, ganho de peso. O aumento da quantidade e da ação da lipase sugere que as tilápias podem receber dietas com maiores quantidades de lipídeos em temperaturas mais elevadas, poupando os aminoácidos para a função de ganho em carne. Este fator também reduz o incremento calórico, aumentando a energia líquida da dieta.

\section{CONCLUSÕES}

O desempenho e a atividade catalítica da lipase de tilápias do Nilo machos, linhagem 


\section{DESEMPENHO DE TILÁPIAS DO NILO}

tailandesa, são influenciados pela temperatura da água.

Aos $32^{\circ} \mathrm{C}$ de temperatura, as tilápias apresentaram maior ganho de peso e melhor

\section{BIBLIOGRAFIA}

Azevedo, P.A., Cho, C.Y. and Leeson, S. 1998. Effects of feeding level and water temperatura on growth, nutrient and energy utilization and waste outputs of rainbow trout (Oncorhynchus mykiss). Aquat Living Resour, 11: 227-238.

Baldisseroto, B. 2002. Fisiologia de peixes aplicada à piscicultura. UFSM. Santa Maria. 212 pp.

Boyd, C.E. 1982. Water quality management for pond fish culture? Developments in aquaculture and fisheries science, vol. 9. Elsevier Science Publishers B.V. Amsterdam. 318 pp.

Cherry, I.S. and Crandall Jr., L.A. 1932. The specificity of pancreatic lipase: Its appearance in the blood after pancreatic injury. Am J Physiol, 100: 266-273.

Dias-Koberstein, T.C.R., Carneiro, D.J. e Urbinati, E.C. 2004. Comportamento alimentar de alevinos de pacu (Piaractus mesopotamicus, Holmberg, 1887) por meio das observações do tempo de retorno do apetite e do tempo de saciação dos peixes em duas temperaturas de cultivo. Acta Sci Anim Sci, 26: 339-344.

Furuya, W.M., Botaro, D. e Santos, V.G. 2006 Exigências de lisina digestível para juvenis de tilápia-do-Nilo. Rev Bras Zootecn, 35: 937-942.

Justin, K.C., Padre, R.G., Hayashi, C., Soares, C.M., Visentainer, J.V., Souza, N.E. e Matsushita, M. 2005. Efeito da temperatura da água sobre desempenho e perfil de ácidos graxos de tilápia do Nilo (Oreochromis niloticus). Acta Sci Anim Sci, 27: 529-534.

Kikuchi, K., Iwata, N., Kawabata, T. and Yanagawa, T. 2006. Effect of feeding frequency, water temperature, and stocking density on the growth of tiger puffer, takifugu rubripes. J World Aquacult Soc, 37: 12-20.

Koven, W.M., Van Anholt, R., Lutzky, S., Ben-Atia, I., Nixon, O., Ron, B. and Tandler, A. 2003. The effect of dietary arachidonic acid on growth, survival, and cortisol levels in different-age gilthead seabream larvae (Sparus aurata) exposed to handling or daily salinity change. conversão alimentar. Além disso, nesta mesma temperatura, ocorreu a maior atividade de lipase e a maior atividade específica de lipase.

Aquaculture, 228: 307-320.

Kubitza, F. 2000. Tilápia-Tecnologia e planejamento na produção pomercial. Fernando Kubitza. Jundiaí. 289 pp.

Moura, G.S., Oliveira, M.G.A. e Lanna, E.A.T. 2009. Atividade de tripsina no quimo de tilápiatailandesa submetida a diferentes temperaturas da água. Rev Bras Zootecn, 38: 2086-2090.

NRC. 1994. National Research Council. Nutrient requirements of poultry. $9^{\text {th }}$ ed. revised. National Academy Press. Washington.

Okamoto, M.H., Sampaio, L.A. e Maçada, A.P. 2006. Efeito da temperatura sobre o crescimento e a sobrevivência de juvenis da tainha Mugil platanus Gunther, 1880. Rev Atlântica, 28: 6166.

Piedras, S.R.N., Moraes, P.R.R. e Pouey, J.L.O.F. 2004. Crescimento de juvenis de jundiá (Rhamdia quelen) de acordo com a temperatura da água. B I Pesca, 30: 177-182.

Piedras, S.R.N., Moraes, P.R.R. e Pouey, J.L.O.F. 2006. Desempenho de juvenis de catfish (Ictalurus punctatus) em diferentes temperaturas. Rev Bras Agroc, 12: 367-370.

Piper, R.G., Mcelwain, I.B. and Orme, L.E. 1982. Fish Hatchery Management. Department of Interior. Washington. U.S. 517 pp.

Ribeiro, F.B., Lanna, E.A.T. e Bomfim, M.A.D. 2006. Níveis de fósforo total em dietas para alevinos de tilápia do Nilo. Rev Bras Zootecn, 35: 1488-1593.

Rostagno, H.S., Albino, L.F.T. e Donzele, J.L. 2005. Tabelas brasileiras para aves e suínos: composição de alimentos e exigências nutricionais. Universidade Federal de Viçosa, Viçosa, MG. $186 \mathrm{pp}$.

Seixas Filho, J.T. Oliveira, M.G.A., Donzele, J.L., Gomide, A.T.M. e Menin, E. 2000. Atividade de lipase em quimo de três espécies tropicais de peixes Teleostei de água doce. Rev Bras Zootecn, 29: 6-14.

Silva, E.C.S. e Araújo Lima, C.A.R.M. 2003. 


\section{MOURA, OLIVEIRAELANNA}

Influência do tipo de alimento e da temperatura na evacuação gástrica da piranha caju (Pygocentrus nattereri) em condições experimentais. Acta Amazônica, 33: 145-156.

Sklan, D., Prag, T. and Lupatsch, I. 2004. Structure and function of the small intestine of the tilapia Oreochromis niloticus $\mathrm{x}$ Oreochromis aureus (Teleostei, Cichlidae). Aquac Res, 35: 350-357. Tidwell, J.H., Coyle, S.D., Bright, L.A., Arnum, A.V. and Yasharian, D. 2003. Effect of water temperature on growth, survival, and biochemical composition of largemouth bass
Micropterus salmoides. J World Aquacult Soc, 34: 175-183.

UFV. 2004. Sistemas para análises estatísticas e genéticas. Versão 9,0. Fundação Arthur Bernardes. Viçosa, MG.

Usmani, N. and Jafri, A.K. 2002. Effect of fish size and temperature on the utilization of different protein sources in two catfish species. Aquac Res, 33: 959-967.

Warburg, O. und Christian, W. 1941. Isohering und kristallisation des gõrungs ferments enolase. Biochem Zool, 310: 384-421.

Archivos de zootecnia vol. 61, núm. 235, p. 374. 